\title{
O INTÉRPRETE DE LIBRAS NO CONTEXTO DO ENSINO SUPERIOR
}

\author{
Ronaldo Quirino da Silva \\ Ana Cristina Guarinello \\ Sandra Eli Sartoreto de Oliveira Martins ${ }^{(*)}$
}

\section{INTRODUÇÃO}

Esta pesquisa tem como base os dados de Censo de Educação Superior de 2014, os quais revelam que, nesse ano, havia 7.828.013 pessoas matriculadas em cursos universitários. Em complemento a esses dados, os Microdados do Censo da Educação Superior (INEP, 2014) deflagram que, desse total, 33.377 se declararam pessoas com deficiência, sendo consideradas como um dos segmentos populacionais, caracterizado pelas Políticas Nacionais de Educação Inclusiva como público-alvo da Educação Especial.

A esse respeito, de acordo com os estudos de Silva (2016), pode-se afirmar que esse número (33.377) ainda é ínfimo, diante da parcela do público geral que está matriculada em cursos de nível superior. Isso ocorre porque a matrícula desse contingente corresponde a menos de $1 \%$ da população acadêmica universitária, representando somente $0,43 \%$ dos estudantes que frequentam a educação superior. Tais fatos parecem indicar que, apesar dos avanços que se tornaram possíveis, por meio das políticas educacionais para as pessoas com deficiência, percebe-se uma lacuna no que se refere a sua inserção na educação superior, quando comparada à população geral.

\footnotetext{
${ }^{(*)}$ Ronaldo Quirino da Silva. Mestre em Distúrbio da Comunicação, especialista em Educação Bilíngue para Surdos, Libras /Lingua Portuguesa, Graduado em Pedagogia pela Universidade Cidade de São Paulo (2009). Professor Intérprete - Universidade Positivo de 2009. E-mail: roncarioca@ hotmail.com.

Ana Cristina Guarinello. Graduada em Fonoaudiologia pela Pontifícia Universidade Católica do Paraná (PUC-PR, 1992), Mestrado em Educação pela Universidade de Bristol (1994) e Doutorado em Estudos Linguísticos pela Universidade Federal do Paraná (UFPR, 2004). Atualmente é professora do curso de Graduação em Fonoaudiologia e do Mestrado e Doutorado em Distúrbios da Comunicação da Universidade Tuiuti do Paraná. E-mail: ana.guarinello@utp.br.

Sandra Eli S. Martins. Pedagoga e doutora em Educação. Professora do Departamento de Educação Especial e do Programa de Pós-Graduação em Educação, da Faculdade de Filosofia e Ciências da Universidade Estadual Paulista (Unesp), Campus de Marília. Atualmente cursa pós-doutorado no Programa de Linguística da UFSCar. E-mail: sandreli@marilia.unesp.br.
} 
Esse aumento de procura por matrículas pode ser a resposta às políticas públicas que levam em conta a inclusão não só de pessoas com deficiência, mas também das pessoas das mais diferentes esferas sociais e com múltiplas necessidades educacionais específicas de caráter permanente e/ou temporário, decorrentes das barreiras existentes nos ambientes educacionais de ensino. Além dessas, várias políticas afirmativas também contribuíram para esse aumento, como a Lei de Cotas 12.711/12, a qual garante a reserva de 50\% das vagas em instituições do ensino superior público e privado, que serão subdivididas entre alunos negros e aqueles oriundos integralmente do ensino médio público regular e/ou de EJA, desde que comprovada uma renda familiar mínima de até um salário e meio. Também os programas Prouni, Enem, Fies e Reuni objetivam o acesso e a permanência desses alunos à educação superior.

No que diz respeito à acessibilidade de estudantes surdos ao ensino superior, este trabalho enfatizará a função dos intérpretes de língua de sinais, como responsáveis por promover a interação discursiva entre os surdos e ouvintes nas relações acadêmicas e sociais, no contexto universitário. O reconhecimento desse profissional decorre de movimentos sociais da comunidade surda, educadores e profissionais de áreas afins, que defendem sua escolarização em espaços bilíngues, nos quais a instrução e o conhecimento curricular devem ocorrer por meio da Língua Brasileira de Sinais conforme definido no Decreto 5.626/2005. Esse documento refere que as instituições federais de ensino, desde a educação básica até a educação superior, devem incluir, em seus quadros, o tradutor e intérprete de Libras -Língua Portuguesa ${ }^{1}$, nos serviços e instituições públicas e privadas nas áreas da educação, saúde e cultura/lazer, entre outros.

Cabe ressaltar que a profissão de intérprete de Libras foi apenas recentemente considerada pela Lei 12.319/2010, a qual regulamenta a profissão de Tradutor e Intérprete da Língua Brasileira de Sinais (TILS). Todavia, antes mesmo de tal lei ser regulamentada, o movimento político em favor da inclusão de pessoas com deficiência, preferencialmente, no sistema regular de ensino - da educação infantil ao ensino superior - indica, desde a década de 1990, o direito de os surdos usufruírem dos serviços do profissional tradutor/intérprete da Libras nos espaços educacionais,

\footnotetext{
1 Cabe esclarecer que, no decorrer deste trabalho, iremos nos referir aos intérpretes utilizando os termos Tradutor/Intérprete de Língua de Sinais (TILS), como o faz o Decreto 5.626/05, ao se referir à função desse profissional.
} 
reiterando a obrigatoriedade da contratação desse profissional, através da promulgação das legislações referenciadas.

Antes da década de 1980, sabe-se que, no Brasil, a função desse profissional era exercida por pessoas que atuavam na informalidade, por meio de um trabalho assistencialista, caritativo e voluntário, sem reconhecimento em termos trabalhistas da sua qualificação em uma carreira profissional. Quadros (2004) e Schubert (2015) enfatizam que, em geral, atuavam em instituições religiosas e nas relações familiares e de amizade com os surdos.

Com destaque para a atuação desse profissional no campo educacional, Lacerda (2003) esclarece que esta se alarga para a de educador e parceiro na construção dos conhecimentos partilhados pela escola, denominando-o intérprete educacional. Em seus estudos (2003, 2009) postula que sua contratação somente deve ocorrer desde o $5^{\circ}$ ano do Ensino Fundamental, conforme proposto pelo Decreto 5.626/05, recomendando que, na fase anterior a essa etapa de ensino, os surdos devem estudar em escolas especiais para surdos e/ou classes bilíngues, em contextos inclusivos. A partir do quinto ano do Ensino Fundamental, caberá ao professor ouvinte ministrar suas aulas sem preocupar-se em como passar esta ou aquela informação em sinais, atuando na língua de que tem domínio, devendo o intérprete traduzir as aulas do português oral para a língua de sinais.

Defensores dessa perspectiva acrescentam que a atuação desse profissional vai além de interpretar e traduzir de uma língua para outra. Caberá a ele promover interação discursiva entre surdos/ouvintes em sala de aula, pois, além de dominar as formas gramaticais e de uso de duas línguas, os intérpretes devem demonstrar capacidade de transitar nos contextos culturais, políticos e educacionais nos quais os falantes estão inseridos.

Portanto, o reconhecimento do intérprete enquanto educador, na escola, se distancia da visão equivocada que o percebe como recurso e/ou instrumento comunicativo para ser considerado capaz de possibilitar aos sujeitos que enunciam a constituição de sentidos, através do uso de línguas diferentes.

Em outras palavras, o ato de interpretar não consiste somente em traduzir de uma língua para outra língua, porém, há um sujeito singular que irá atribuir sentidos entre essas duas línguas, o que demonstra não existir neutralidade e nem linearidade na linguagem. Ao dar sentidos ao 
discurso, cada profissional toma uma posição enunciativa, de sorte a produzir outro discurso por meio da tradução, fazendo escolhas de vocabulários e expressões, na sua singularidade, na tentativa de fazer com que o aluno surdo tenha uma relação mais dialógica em sala de aula. Na esteira de Bakhtin (2004), percebe-se que são nas relações dialógicas, sociais que ocorrem as interações sociais e linguísticas que os homens estabelecem entre si, tendo essas interações um papel fundamental entre o sujeito e o outro, reconhecendo a alteridade de ambos os envolvidos; assim, o “eu” só passa a existir em contato e por causa do "outro" (BAKHTIN, 2004).

Desse modo, esse profissional necessitará de qualificação e formação adequadas para transitar nos mais variados contextos discursivos. Nessa direção, Schubert (2012) e Nantes (2012) lembram que esse profissional assumirá múltiplos papéis nas suas atividades diárias, que, em geral, vão além do ato de interpretar e traduzir e que dependem de vários fatores, desde educacionais até sociais, podendo extrapolar as relações acadêmicas.

Problematizando a prática da tradução/interpretação em sala de aula, Lacerda (2012) esclarece ainda ser necessário que esse profissional faça uma adequação linguística, nas diferentes disciplinas; reconheça as variações da língua, quanto a diferentes faixas etárias, grupos sociais, localização geográfica etc.; compreenda os aspectos da língua oral/escrita usada pelos ouvintes, os quais influenciam a língua de sinais em contextos mais formais, quando há a necessidade de termos técnicos ou especializados, obrigando o intérprete, muitas vezes, a usar datilologia ou paráfrases, explicando o sentido pretendido.

Ao correlacionar as atribuições e competências desse profissional para o exercício da função, na Educação Superior, deve-se levar em conta a densidade lexical de conteúdos relacionados à formação universitária, o que torna sua atuação mais complexa, uma vez que tomará decisões importantes sobre quais itens lexicais vai privilegiar, a fim de que a interação discursiva ocorra.

Redirecionando essas discussões para o contexto universitário, Silva (2013) revela, em seu estudo, que esse profissional enfrentará inúmeros desafios, dentre os quais destaca o nível de proficiência dos estudantes surdos na língua de sinais. De modo geral, caberá a ele identificar as necessidades educacionais e enunciativas dos acadêmicos surdos, devendo apresentar outros recursos comunicacionais, como, por exemplo, o português sinalizado, quando for necessário. 
Nesse contexto, será de sua responsabilidade favorecer e promover o debate e a reflexão sobre práticas excludentes, contribuindo para amenizar as barreiras atitudinais consolidadas historicamente em torno da surdez, dos surdos e do seu modo singular de se reconhecer enquanto pertencente a um grupo linguístico minoritário, em nosso país. Em reconhecimento e defesa pelo direito fundamental de acesso à Educação Superior aos surdos, o texto em questão objetiva analisar a percepção dos intérpretes de Libras sobre as suas atribuições e práticas profissionais, no ensino superior. Trata-se de um recorte de uma pesquisa mais ampla realizada junto ao Programa de Distúrbios da Comunicação, na Universidade Tuiuti do Paraná. ${ }^{2}$

\section{PASSOS PERCORRIDOS NA REALIZAÇÃO DO ESTUDO}

Constituíram a amostra deste estudo 35 tradutores/intérpretes de língua de sinais, a maioria dos quais trabalha em instituições privadas e públicas na cidade de Curitiba e na região Sul e Sudeste do país, sendo que o critério para inclusão era atuar ou já ter atuado no ensino superior.

Os participantes responderam a um questionário contendo vinte e sete questões abertas e fechadas, que discorriam a respeito de sua formação, do papel que exercem nas instituições de ensino superior em que atuam, de suas funções como intérprete, das dificuldades que enfrentam em sala de aula.

Os questionários foram enviados eletronicamente para intérpretes, os quais preenchiam os critérios de inclusão desta pesquisa; aos intérpretes que atuavam em Curitiba, foram entregues pessoalmente. Todos os intérpretes deveriam responder individualmente o questionário e assinar o termo de consentimento livre e esclarecido, no qual os objetivos da pesquisa estavam explicitados.

A aplicação do instrumento para os participantes que residiam em Curitiba foi realizada por um dos proponentes deste estudo, em locais escolhidos por ambas as partes. Os profissionais participantes trabalhavam em IES públicas e privadas, nas quais se concentrava o maior número de alunos surdos matriculados em cursos específicos de graduação. Os questionários foram respondidos por todos os participantes por escrito, sem a interferência do pesquisador.

\footnotetext{
${ }^{2}$ Essa dissertação integra um projeto em rede financiado pelo Programa Observatório da Educação (Edital/Capes 49/2012), com a participação de diversas universidades brasileiras.
} 
Para as variáveis qualitativas, foram consideradas as frequências absolutas e relativas, sendo desenvolvida uma discussão a partir da Análise de Conteúdo proposta por Bardin (2011). Conforme Bardin, a aplicação dessa técnica envolve três etapas básicas - pré-análise, descrição analítica e interpretação inferencial - adotadas no tratamento dos dados, ao se compor sua apresentação, em tabelas, expostas no próximo tópico deste trabalho.

\section{RESULTADOS E DISCUSSÃO}

Com relação à caracterização da amostra, cabe esclarecer que fizeram parte deste estudo 35 participantes, sendo 74,2\% $(\mathrm{n}=26)$ do sexo feminino e $25,71 \%(\mathrm{n}=9)$ do sexo masculino. Com relação à idade da amostra, 13 participantes tinham entre 20 e 30 anos, 12 entre 31 e 40 anos, 9 entre 41 e 50 anos e apenas 1 acima de 51 anos.

Antes de os participantes responderem sobre sua atuação e formação, no ensino superior, foram questionados sobre onde aprenderam a língua de sinais. Dos 35 participantes, 24 afirmaram que aprenderam no ambiente familiar, religioso ou com amigos surdos, enquanto onze fizeram cursos de capacitação.

Os dados da Tabela 1 demonstram que a maioria desses profissionais utilizava a língua de sinais pelo menos cinco anos antes da realização deste estudo, ou seja, antes da oficialização das leis que regulamentam essa língua, a saber, Lei 10.436/02 e Decreto 5.626/05, no seu art. $3^{\circ}$. Tais respostas coadunam com a literatura da área (QUADROS; PERLIN, 2008), que identifica ter ocorrido a atuação desses profissionais nos espaços de relações sociais informais, como na igreja e na família, porém, de forma voluntária, possibilitando a profissionalização desses sujeitos.

TABELA 1. Distribuição da amostra segundo o tempo de uso da língua de sinais

\begin{tabular}{l|l|l}
\hline TEMPO (ANOS) & N & $\%$ \\
\hline 5 a 10 anos & 13 & $37,14 \%$ \\
11 a 15 anos & 11 & $31,42 \%$ \\
16 a 20 anos & 5 & $14,28 \%$ \\
21 a 25 anos & 2 & $5.71 \%$ \\
26 a 30 anos & 4 & $11,42 \%$ \\
TOTAL & 35 & $100,0 \%$ \\
\hline
\end{tabular}

Fonte: O Autor/ 2015. 
Quanto aos anos de atuação no ensino superior, na Tabela 2, é possível visualizar que vários intérpretes já vinham atuando no ensino superior antes mesmo da Lei 12.319 , de $1^{\circ}$ de setembro de 2010, que passou a reconhecer o profissional tradutor/intérprete de Libras. É importante reconhecer que, nesta amostra, foi possível visualizar que da maioria dos intérpretes atuou no ensino superior após a regularização do Decreto 5626, o qual tornou obrigatória a presença desses profissionais em todos os níveis de ensino, inclusive no superior, possibilitando regulamentar sua contratação pelas IES, a partir de 2005.

Tabela 2. Distribuição da amostra segundo o tempo de atuação em IES

\begin{tabular}{l|l|l}
\hline TEMPO (ANOS) & N & $\%$ \\
\hline 1 a 3 anos & 15 & $42,8 \%$ \\
4 a 6 anos & 16 & $45,7 \%$ \\
7 a 8 anos & 4 & $11,42 \%$ \\
TOTAL & 35 & $100,0 \%$ \\
\hline
\end{tabular}

Fonte: O Autor / 2015.

Com relação à formação acadêmica da amostra, foi possível notar que a formação em curso superior foi obtida posteriormente ao ingresso na profissão. Do total dos participantes, $100 \%$ revelaram formação em nível de especialização lato sensu, dos quais 30 responderam ter curso de pós-graduação na área da surdez e/ou áreas afins, representando 74,2\%; cinco participantes, ou seja, 14,2\%, possuem Mestrado - dois em Distúrbios da Comunicação, dois em Educação e um em Comunicação Social. Nesse quesito da amostra geral, nove informaram ter concluído também a graduação no curso de Letras-Libras.

Quando foram questionados acerca do conhecimento que tinham das atribuições para o exercício da função de intérprete, $36,8 \%$ dos participantes responderam que estas se caracterizavam pela atividade de interpretar e intermediar a comunicação entre os surdos e ouvintes, 31,6\% revelaram que conheciam suas atribuições, mas não justificaram sua resposta, 13,2\% indicaram que se trata de favorecer a inclusão e a autonomia do aluno surdo, nos espaços educacionais, 7,9\% responderam que suas atribuições se relacionam com a busca de conhecimento e de aperfeiçoamento, 5,3\% consideram que uma das atribuições é fazer a interação discursiva entre os 
sujeitos, 2,6\% ressaltaram que devem orientar o aluno surdo nos estudos, enquanto 2,6\% afirmaram ampliar a atividade de tradução no ensino superior, conforme se observa a seguir.

Tabela 3. Distribuição da amostra em relação às atribuições como intérprete

\begin{tabular}{l|c|c}
\hline RESPOSTA & FREQUÊN & \% \\
& CIA & 36,8\% \\
Traduzir e interpretar, intermediar comunicação & 14 & $13,2 \%$ \\
entre surdos e ouvintes & 5 & $7,9 \%$ \\
Promover autonomia e inclusão do aluno surdo & 3 & $5,3 \%$ \\
Buscar conhecimento e aperfeiçoamento & 2 & $2,6 \%$ \\
Objeto/ponte de comunicação & 1 & $2,6 \%$ \\
Orientar o aluno surdo nos seus estudos & 1 & $31,6 \%$ \\
Ampliar atividade de tradução no ensino superior & 12 & $\mathbf{1 0 0 , 0 \%}$ \\
Não resposta & $\mathbf{3 8}$ & \\
TOTAL & & \\
\hline
\end{tabular}

Fonte: O Autor / 2015. Nota: Questão com alternativas múltiplas.

De modo geral, as respostas dos participantes na Tabela 3 combinam com as do intérprete educacional, referidas pela literatura na área da surdez (LACERDA, 2003, 2009). Enfatizam, nesse contexto, que uma das atribuições principais corresponde à mediação discursiva entre os interlocutores surdos e ouvintes, favorecendo a autonomia e a interação dos surdos com os sujeitos ouvintes que circulam nos espaços educacionais.

Uma pequena parcela da amostra caracteriza sua função como instrumento de comunicação, na medida em que concebe que o papel do intérprete é traduzir de uma língua-fonte para uma língua-alvo. Tal compreensão diverge das defendidas pelos autores da área da surdez, referenciados neste texto, visto que o papel e as atribuições do intérprete nas IES se constituem como uma atividade profissional extremamente nova e complexa. A esse respeito, Schubert (2015) complementa que a principal atribuição deve estar relacionada à percepção dos mesmos sobre suas próprias funções, o que extrapola uma visão mais restrita de língua como instrumento de comunicação, para alargar sua compreensão enquanto fenômeno ideológico de linguagem, o qual visa à constituição de sentidos entre os usuários desses sistemas linguísticos. 
É preciso esclarecer que essa percepção sobre a Libras como instrumento pode estar associada ao modo como tem sido abordada nos documentos legais que orientam o exercício da profissão. Há que se considerar, portanto, que o papel do intérprete não se restringe à transferência de informações de uma língua para outra, mas extrapola o domínio linguístico da mesma, fato que lhe exige habilidades de circular e transitar em contextos situacionais e culturais de um grupo constituído por sujeitos que não ouvem.

Nesse sentido, chama a atenção o fato de $31,6 \%$ dos participantes não terem respondido à questão sobre quais são suas atribuições como intérpretes, deixando-a em branco, ou seja, não se posicionaram acerca dessa temática - o que é ser intérprete. Dito de outro modo, compreender a complexidade de suas tarefas possibilitará a esse grupo empoderar-se dos direitos de melhores condições de trabalho para o exercício da profissão, em ambientes nas mais variadas etapas de ensino. Entender a notoriedade da sua presença em sala de aula é condição sine qua non para exercê-la com competência e fluidez.

A falta de espaços para dialogar sobre o seu fazer diário pode dificultar o reconhecimento da profissão e, às vezes, confundir o seu oficio profissional com o do professor. Este, por sua vez, em colaboração com o intérprete, promoverá a oferta de estratégias que maximizem as potencialidades do educando surdo. Destarte, essa parceria extrapola a atividade de transposição linguística de um texto e/ou de uma língua para outra, pois, nas práticas discursivas, o ato de interpretar, ensinar e aprender é indissociável do processo de constituição de sentidos e desenvolvimento humano.

A propósito das percepções dos participantes sobre o trabalho em parceria com o professor em sala de aula, a maioria dos participantes refere que os mesmos, em geral, optam por deixar a aprendizagem dos alunos surdos a cargo de sua responsabilidade, reiterando os achados da literatura (LACERDA, 2012). Esses estudos acrescentam que, dentre os problemas mais recorrentes, está a falta de compreensão sobre a necessidade de: a) oferta antecipada dos conteúdos curriculares que serão ministrados nas aulas; b) participação desses profissionais na elaboração planejamento curricular.

Ainda sobre a percepção dos intérpretes acerca das dificuldades que enfrentam em sala de aula para interpretar, $57,6 \%$ destacam que estas estão relacionadas à falta de domínio do 
vocabulário específico dos cursos nos quais atuam, 12,2\%, à ausência do acesso aos conteúdos curriculares de forma antecipada, 7,6\%, à tradução de vídeos sem legenda, 4,5\%, à tradução do léxico em língua estrangeira e $3 \%$, à produção de fala acelerada do professor, conforme se pode notar na tabela a seguir.

Tabela 4 - Distribuição da amostra segundo as dificuldades durante a interpretação

\begin{tabular}{|c|c|c|c|}
\hline RESPOSTA & FREQUÊNCIA & & $\%$ \\
\hline Vocabulário específico & 21 & & 57,6 \\
\hline Traduzir vídeos sem legendas & 5 & & $7,6 \%$ \\
\hline Falta de conhecimento prévio dos conteúdos & 4 & & 12,2 \\
\hline Palavras em outro idioma & 3 & & $4,5 \%$ \\
\hline Velocidade da fala do professor & 2 & & $3,0 \%$ \\
\hline Falta de intérprete de apoio & 1 & & $1,5 \%$ \\
\hline Não sente dificuldade para interpretar & 9 & & 13,6 \\
\hline TOTAL & 66 & $\begin{array}{l}\% \\
\%\end{array}$ & 100,0 \\
\hline
\end{tabular}

Fonte: O Autor / 2015. Nota: Questão com alternativas múltiplas.

As dificuldades relatadas pelos participantes conferem aos aspectos tradutórios intrínsecos dos processos discursivos a competência do se sentir imerso em diferentes contextos linguísticos de áreas/disciplinas do conhecimento científico e de formação acadêmica, definida como natural do ato de interpretar, conforme apontado por Quadros (2004), Lacerda (2002) e Silva (2016).

A esse respeito, Lacerda (2012) acrescenta ser preciso ponderar que a presença desse profissional não seja denominada como único ato responsável das instituições de ensino, pela organização de espaços educacionais inclusivos.

\section{CONSIDERAÇÕES FINAIS}

Os resultados possibilitaram afirmar que a presença do tradutor/intérprete tem sido uma prática recorrente, na Educação Superior, atendendo às normativas que legislam sobre o tema Decreto 5.626/05 e Lei 12.319/2010. Por outro lado, indicam as dificuldades desses profissionais em reconhecer sua atuação como protagonistas desse processo em favor dos avanços da educação bilíngue para surdos, em contextos inclusivos. Dessa maneira, é preciso que sejam criados novos espaços específicos para fomentar o diálogo dos atores desse processo, redirecionados à problematização das atribuições desse profissional, na universidade. Espera-se que a reflexão 
compartilhada neste texto acerca da prática desse profissional, no ensino superior, contribua para alargar os sentidos e significados da importância da sua atuação na mediação da apropriação dos conhecimentos científicos/acadêmicos pelos surdos inseridos nos espaços educacionais, e na universidade não é diferente. 


\section{REFERÊNCIAS}

BAKHTIN, Mikhail (Volochinov). Marxismo e filosofia da linguagem. São Paulo: Hucitec, 2004.

BARDIN, I. Análise de conteúdo. Lisboa: Edições Setenta, 2011.

BERBERIAN, A.P.; GUARINELLO, A.C.; EYNG, D.B. Professores ouvintes e intérpretes de Libras: Mediadoresparceiros do processo educacional dos surdos. IN: GIROTO, C.R.M.; MARTINS, S.E.S.O.; BERBERIAN, A.P. (Orgs.). Surdez e educação inclusiva. São Paulo: Cultura Acadêmica, 2012. p.79-96.

BRASIL MEC/SEB. Lei 10.436, de 24 abr. 2002. Dispõe Sobre A Língua Brasileira De Sinais - Libras. Diário Oficial da União. Poder Legislativo, Brasília, 25 abr.202, p. 23.

BRASIL. MEC/SEE. Dec. 5.626 de 22 dez.2005. Regulamenta a Lei 10.436/2002, que dispõe sobre a Língua Brasileira de Sinais - Libras. Diário Oficial da União. Poder Executivo, Brasília, 23 dez. 2005. p. 28.

BRASIL. MEC/SEESP. Secretaria de Educação Especial. Política Nacional de Educação Especial na Perspectiva da Educação Inclusiva. Brasília: MEC/SEESP, 2007.

BRASIL. MEC. Lei 12.319, de $1^{\circ}$ set. 2010. Regulamenta a profissão de Tradutor e Intérprete da Língua Brasileira de Sinais - LIBRAS. Diário Oficial da União. Poder Legislativo, Brasília, 02 set. 2010. p. 01.

MEC/INEP. Principais Indicadores da Educação de Pessoas com Deficiência. Censo MEC/INEP 2015.

Disp.: <http://portal.mec.gov.br/index.php?option=com_docman\&view=download\&alias=17655-secadi-principaisindicadores-da-educacao-especial\&category_slug=junho-2015-pdf\&Itemid=30192>. Acesso: 06 fev. 2016.

MEC/INEP. Divulgados sinopse e microdados do Censo de 2014. Assessoria de Comunicação Social. 02 fev. 2016. Disp.: <http://portal.inep.gov.br/visualizar/-/asset_publisher/6AhJ/content/divulgados-sinopse-e-microdadosdo-censo-de-014?redirect=http\%3A\%2F\%2Fportal.inep.gov.br\%2Fvisualizar\%3Fp_p_id\%3D101_INSTAN6AhJ \%26 p_p_lifecycle\%3D0\%26p_p_state\%3Dnormal\%26p_p_mode\%3Dview\%26p_p_col_id\%3Dcolumn2\%26p_p_col_pos \%3D1\%26p_p_col_count\%3D2\%26p_r_p_564233524_tag\%3Ddestaque>. Acesso: 03 fev. 2016.

GUARINELlO, A. C. et al. O intérprete universitário da língua brasileira de sinais na cidade de Curitiba. Revista Brasileira de Educação Especial, v. 14, n.1, p. 63-74, 2008.

LACERDA, C.B.F. Inclusão escolar de alunos surdos: o que dizem alunos, professores e intérpretes sobre esta experiência. Pelotas: Editora Pelotas, 2000.

O intérprete educacional de língua de sinais no ensino fundamental: refletindo sobre limites e possibilidades. In: LODI, A. C.; HARRISON, K. P.; CAMPOS, S. L.; OTTMAR, T. (Orgs.). Letramento e Minorias. Porto Alegre: Mediação, 2002. p. 120-128.

A escola inclusiva para surdos: refletindo sobre o intérprete de língua de sinais em sala de aula. Relatório Final referente a bolsa de Pós-Doutorado no exterior apresentado à FAPESP. Processo 01/10256-5, 2003.

Intérprete de LIBRAS: em atuação na educação infantil e no ensino fundamental. 1. ed. Porto Alegre: Mediação/FAPESP, 2009. v. 1.

O intérprete de Língua Brasileira de Sinais (ILS). IN: LODI, A.C.B.; MÉLO, A.D.B.; FERNANDES, E. (Orgs.). Letramento, bilinguismo e educação de surdos. Porto Alegre: Mediação, 2012. p. 247-288.

NANTES, J.M. A constituição do intérprete de língua de sinais no Ensino Superior na perspectiva dos surdos: o cuidado de si e do outro. 2012. 103f. Dissertação (Mestrado em Educação) - Faculdade de Educação da Universidade Federal da Grande Dourados (UFGD), Dourados, MS, 2012.

QUADROS, R.M. O Tradutor Intérprete de Língua Brasileira de Sinais e Língua Portuguesa. Distrito Federal: Programa Nacional de Apoio à Educação do Surdos, 2004.

; PERLIN, G. Estudos Surdos I, II, III. Petrópolis: Arara Azul, 2008. 
SCHUBERT. S.E.M. Políticas públicas e os sentidos e significados atribuídos pelos educandos surdos ao intérprete de língua de sinais brasileira. 2012. 205f. Dissertação (Mestrado em Educação) - UniversidadeTuiuti do Paraná, Curitiba, 2012.

Entre a Surdez e a Língua: outros sujeitos, novas relações. Curitiba: Prismas, 2015.

SILVA, D. S. A atuação do intérprete de Libras em uma Instituição de Ensino Superior. 2013. 161f. Dissertação (Mestrado em Educação Brasileira) - Universidade Federal do Ceará, Fortaleza, 2013.

SILVA, K.C. Condições de Acessibilidade Na Universidade: o ponto de vista de estudantes com deficiência. 2016.149f. Dissertação (Mestrado em Educação) - Universidade Estadual Paulista "Júlio de Mesquita Filho", Marília, 2016.

SILVA, R.Q. O intérprete de Libras no contexto do ensino superior. 2016. 76f. Dissertação (Mestrado em Distúrbios da Comunicação) - Universidade Tuiuti do Paraná, Curitiba, 2016. 


\section{RESUMO}

Pessoas surdas têm o direito de ter o acompanhamento de um profissional tradutor/intérprete de língua de sinais, nas instituições federais de ensino superior, as quais devem garantir acesso à comunicação, à informação e à educação nos processos seletivos, nas atividades e nos conteúdos curriculares. Em vista disso, este artigo objetiva analisar a percepção de intérpretes de Libras a respeito do seu papel e suas práticas, nessa etapa de ensino. Para tanto, 35 intérpretes de Libras atuantes em Instituições de Ensino Superior responderam a um questionário, composto de questões abertas e fechadas, a respeito dessa temática. Os resultados indicam algumas dificuldades que esses profissionais encontram, nesse nível de ensino, e possíveis caminhos para ampliar suas possibilidades de atuação no processo de acessibilidade dos surdos.

Palavras-chave: Intérpretes. Ensino superior. Acessibilidade. Libras.

\section{LIBRAS INTERPRETER IN HIGHER EDUCATION CONTEXT}

\section{ABSTRACT}

Deaf people have the right to have the accompaniment of a sign language interpreter in federal higher education institutions which should ensure access to communication, information and education in selection processes, activities and curriculum contents. So, this article aims to analyze the perception of Libras interpreters about their roles and practices in this educational level. For this, 35 Libras interpreters from higher education institutions responded a questionnaire composed of open and closed questions regarding this theme. The results indicate some difficulties that these professionals find this level of education and possible ways to expand their possibilities of action in the deaf Accessibility process.

Keywords: Interpreters. Higher education. Accessibility. Libras.

Submetido abril 2016

Aprovado jun. 2016 